\title{
Pulmonary Artery Catheter (PAC) Accuracy and Efficacy Compared with Flow Probe and Transcutaneous Doppler (USCOM): An Ovine Cardiac Output Validation
}

\author{
Robert A. Phillips, ${ }^{1,2}$ Sally G. Hood, ${ }^{3}$ Beverley M. Jacobson, ${ }^{2}$ Malcolm J. West, ${ }^{1}$ \\ Li Wan, ${ }^{3,4}$ and Clive N. May ${ }^{3}$ \\ ${ }^{1}$ School of Medicine, The University of Queensland, Brisbane QLD 3010, Australia \\ ${ }^{2}$ USCOM Ltd., Department of Clinical Science, Sydney NSW 3010, Australia \\ ${ }^{3}$ Howard Florey Institute, University of Melbourne, Parkville VIC 3010, Australia \\ ${ }^{4}$ Department of Pharmacology, University of Melbourne, Parkville VIC 3010, Australia
}

Correspondence should be addressed to Robert A. Phillips, rap.echo@bigpond.com

Received 10 January 2012; Accepted 23 February 2012

Academic Editor: Giuseppe Ristagno

Copyright (C) 2012 Robert A. Phillips et al. This is an open access article distributed under the Creative Commons Attribution License, which permits unrestricted use, distribution, and reproduction in any medium, provided the original work is properly cited.

Background. The pulmonary artery catheter (PAC) is an accepted clinical method of measuring cardiac output (CO) despite no prior validation. The ultrasonic cardiac output monitor (USCOM) is a noninvasive alternative to PAC using Doppler ultrasound (CW). We compared PAC and USCOM CO measurements against a gold standard, the aortic flow probe (FP), in sheep at varying outputs. Methods. Ten conscious sheep, with implanted FPs, had measurements of CO by FP, USCOM, and PAC, at rest and during intervention with inotropes and vasopressors. Results. CO measurements by FP, PAC, and USCOM were $4.0 \pm 1.2 \mathrm{~L} / \mathrm{min}$, $4.8 \pm 1.5 \mathrm{~L} / \mathrm{min}$, and $4.0 \pm 1.4 \mathrm{~L} / \mathrm{min}$, respectively, $(n=280$, range $1.9 \mathrm{~L} / \mathrm{min}$ to $11.7 \mathrm{~L} / \mathrm{min})$. Percentage bias and precision between FP and PAC, and FP and USCOM was -17 and $47 \%$, and 1 and $36 \%$, respectively. PAC under-measured Dobutamine-induced CO changes by $20 \%$ (relative $66 \%$ ) compared with FP, while USCOM measures varied from FP by $3 \%$ (relative 10\%). PAC reliably detected $-30 \%$ but not $+40 \%$ CO changes, as measured by receiver operating characteristic area under the curve (AUC), while USCOM reliably detected $\pm 5 \%$ changes in CO (AUC > 0.70). Conclusions. PAC demonstrated poor accuracy and sensitivity as a measure of CO. USCOM provided equivalent measurements to FP across a sixfold range of outputs, reliably detecting $\pm 5 \%$ changes.

\section{Background}

Since its introduction in 1970 [1], the Swan Ganz pulmonary artery catheter (PAC), using the thermodilution method (TD), has been accepted as a gold standard for the clinical measurement of cardiac output (CO). The PAC has been used to evaluate and guide clinical care, to develop our understanding of physiology and pathophysiology, and as a reference standard for evaluation of novel $\mathrm{CO}$ measurement methods. Despite this widespread application over the last 40 years, it remains essentially without validation and without clinical outcomes benefit [2-5]. Explanations for the absence of PAC effectiveness may be the uncertain accuracy of the method [6-12]. Additionally, PAC TD, using either bolus injections or continuous thermometric monitoring $[1,13$, $14]$, is invasive, with associated patient risks [15-18], and is costly [19].

Given the importance of the circulation in clinical practice, the frequency of clinical interventions, and the limitations of PAC, there is a need for an improved CO measurement and monitoring method. $\mathrm{CO}_{2}$ partial re-breathing [20], breath-to-breath pulmonary blood flow measures [21], arterial pulse pressure analysis [22], and transesophageal Doppler [23] have also been used to measure CO. However, these alternatives have limitations which have precluded significant adoption. A noninvasive, accurate, and effective alternative to PAC may improve clinical care and contribute to our understanding of circulation. 
The Ultrasonic Cardiac Output Monitor, (USCOM) (USCOM 1A, Uscom Ltd., Sydney, NSW, Australia), is a noninvasive, morphometrically calibrated, continuous wave (CW) Doppler ultrasound device which provides an instantaneous, beat-to-beat measure of right- and left-sided CO. CW Doppler is a widely adopted clinical tool with an accuracy measured by Doppler string phantoms of $\pm 2.3 \%$ [24]. USCOM has been compared positively with flow probes in animals [25], with echocardiography from $0.12 \mathrm{~L} / \mathrm{min}$ in neonates [26], in externally driven artificial hearts in orthotopic transplantation [27], with PAC in the postcardiac surgical setting [28-31], and with PAC from 2.14 to $18.7 \mathrm{~L} / \mathrm{min}$ in liver transplantation $[32,33]$. It has acceptable reproducibility in adults and children [34-36], and has been recommended as an alternative to PAC [37].

The ultrasonic transit-time flow probe (FP) is considered a true gold standard method for measuring beat-to-beat $\mathrm{CO}$ with an accuracy of \pm 1 to $2 \%$ [38] but is limited to animal studies as it requires surgical implantation.

This study compared the two clinical methods of $\mathrm{CO}$ measurement, PAC and USCOM, with measures from an implanted FP in conscious sheep to evaluate the relative accuracy and sensitivities of the methods across a range of outputs at baseline and during pharmacologic interventions.

\section{Methods}

2.1. Study Design and Data. The study was approved by the Animal Experimentation Ethics Committee of the Howard Florey Institute. Prior to experiment, 10 adult Merino ewes were anaesthetised with intravenous (i.v.) sodium thiopental (15 mg/kg), and, following intubation, anesthesia was maintained with $1.5-2.0 \%$ isoflurane in oxygen. An incision was made above the fourth left rib, the periosteum stripped, and the rib resected. The pericardium was opened, and the ascending aorta cleared for implantation of a FP $(20 \mathrm{~mm}$, Transonic Systems Inc., Ithaca, NY, USA). The pericardium, periosteum, muscle, and skin were closed in layers. The flow probe cable was tunnelled superficially and exteriorised near the thoracic spine. Antibiotic prophylaxis (900 mg procaine penicillin, Troy Laboratories, NSW, Australia) was administered for three days after surgery. Postsurgical analgesia was maintained with intramuscular injection of flunixin meglumine (1 mg/kg) (Mavlab, Qld, Australia) at the end of surgery, then four and sixteen hours after surgery. A minimum recovery period of fourteen days was allowed prior to any study.

On the day of the study, a single experienced operator inserted a PAC-continuous cardiac output monitor (CCO) (Baxter Healthcare Corp., Irvine, CA, USA) via the right jugular vein into the pulmonary artery under $2 \%$ lignocaine local anesthesia and connected it to a Vigilance Monitor System (Baxter Healthcare Corp., Irvine, CA, USA). With the sheep lying on its right side, both the CO measures from the FP and PAC were captured from the flow meter (Transonics Systems) and the Vigilance, and recorded to computer using a CED micro 1401 interface. FP CO waveforms were acquired at a frequency of $100 \mathrm{~Hz}$ per beat. Ultrasound coupling gel was applied to the skin over the acoustic window between the third and fifth left ribs, and the upper thorax was insonated by a single experienced operator using a $3.3 \mathrm{MHz} \mathrm{CW}$ probe which was manipulated to optimise the transpulmonary Doppler flow profiles on the USCOM monitor. The USCOM device requires the pulmonary valve diameter (PV) to calculate flow volumes, for example, $\mathrm{CO}$ and stroke volume (SV). In human subjects this is determined using a proprietary anthropometric algorithm. An equivalent algorithm is not available for sheep, so for each subject, the USCOM values were calibrated to the FP measurements during a calibration phase prior to experimental measurements, with only post calibration data analysed. The USCOM investigator was blinded to the FP and PAC values, and acquired the Doppler signals and stored the flow profiles to the USCOM hard drive. Each stored screen recorded 6-12 consecutive Doppler profiles, depending on the heart rate (HR). The Doppler profiles were later traced to generate output values for each beat and stored to the USCOM hard drive for later collation and comparison with the corresponding FP and PAC measures.

2.2. Measurement of Outcomes. Contemporaneous CO measurements were made using all methods over a baseline period of up to 40 minutes, during i.v. infusion of the inotrope dobutamine $(0.2,0.4$ and $1.0 \mathrm{mg} / \mathrm{min}$ for $40-$ $50 \mathrm{~min})$, during the postdobutamine recovery phase (10 $\mathrm{min})$, during infusion of the vasopressor arginine vasopressin (AVP) (15 ng/min for $15-20 \mathrm{~min})$, and during a $5 \mathrm{~min}$ post vasopressor phase. The order of dobutamine and AVP infusions was randomised, and a recovery period of 30 minutes between treatments was allowed for CO to return to control levels. As this study compared two beat-to-beat methods, USCOM and FP, against a time averaged method, PAC, 6 to 13 sequential measures of CO by USCOM, and FP were acquired at each comparison point on each subject, depending on heart rate, and averaged to represent the mean $\mathrm{CO}$ values at each time point for comparison with PAC values. Further no time to measurement after intervention was less than 4 minutes, thus allowing PAC time to respond to any $\mathrm{CO}$ changes.

PAC is an uncalibrated method functioning by detection of temperature gradients across a known distance so was not calibrated. However to address any potential for bias, we performed a post hoc calibration of PAC measures to baseline FP values to generate a FP-calibrated PAC series (cPAC), for comparison with FP measures.

2.3. Statistical Analysis. Continuous variables were expressed as mean and standard deviation (SD) and data were analysed using SPSS v.16 (SPSS Inc, Chicago, Ill, USA). Analysis included Bland Altman determination of reliability and reproducibility [39], analysis of means, standard deviations (SD), regression analysis, and Pearson's correlation coefficient. Percentage changes during and after interventions and receiver operator characteristic statistics (ROC) was calculated for PAC and USCOM compared to FP. Area under the ROC curves (AUC) were calculated for 5\% incremental changes in $\mathrm{CO}$ between -40 and $+40 \% \mathrm{CO}$ to determine the sensitivity to change of both methods $[40,41]$ with acceptable sensitivity to change defined as AUC > 0.70 [42]. 


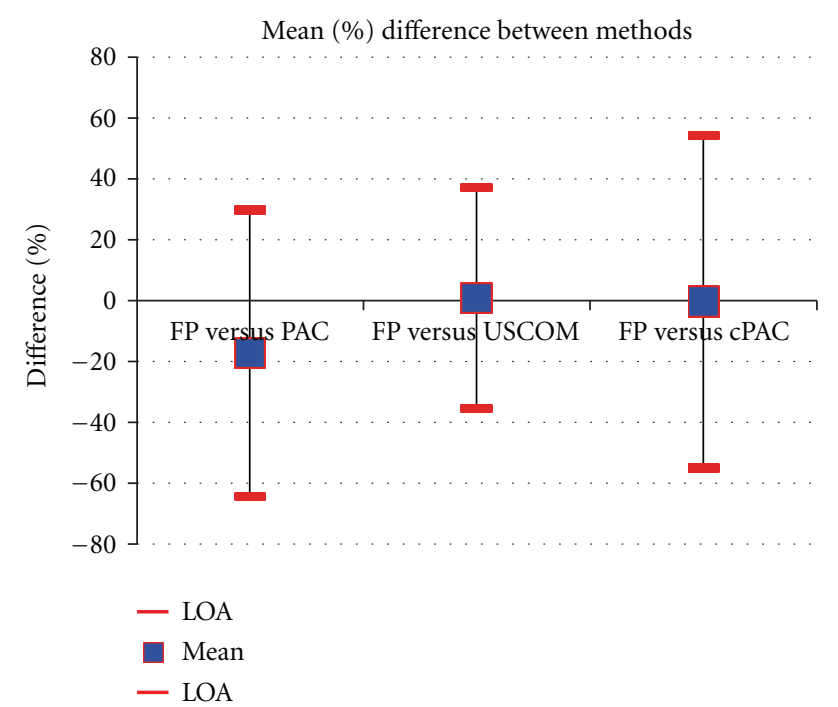

Figure 1: Percentage bias and precision for all paired measures for FP versus PAC $(-17.2 \%$ and $47 \%)$, FP versus USCOM ( $1 \%$ and $36.4 \%)$, and $\mathrm{FP}$ versus $\mathrm{CPAC}(-0.2 \%$ and $54.4 \%)$.

\section{Results}

3.1. Baseline Characteristics and Exclusions. A total of 363 CO measures by FP, 370 measures by USCOM and 293 PAC measures were collected from the 10 adult ewes $(39 \pm 4 \mathrm{~kg})$. PAC failed in $20 \%$ of the experimental acquisitions, while satisfactory FP and USCOM measurements were obtained in all animals and at all time points. Statistical analysis excluded calibration measurements and included only data from contemporaneous, valid, triplicate measures, leaving $280 \mathrm{FP}, \mathrm{PAC}$, and USCOM measures for comparison. A mean of $29 \pm 11$ triplicate measures were completed on each sheep (range 5-42 measures). A further $280 \mathrm{cPAC}$ measures were calculated post hoc by calibrating PAC with baseline FP reference measures to complete the data set.

3.2. Main Outcomes. Mean CO by FP, PAC, USCOM and cPAC across all measures was $4.0 \pm 1.2 \mathrm{~L} / \mathrm{min}$ (range 1.9 to $11.7 / \mathrm{min}$ ), $4.8 \pm 1.5 \mathrm{~L} / \mathrm{min}$ (range 2.5 to $10.1 \mathrm{~L} / \mathrm{min}$ ), $4.0 \pm$ $1.4 \mathrm{~L} / \mathrm{min}$ (range 1.7 to $9.5 \mathrm{~L} / \mathrm{min}$ ), and $4.1 \pm 1.4 \mathrm{~L} / \mathrm{min}$ (range 2.4 to $7.8 \mathrm{~L} / \mathrm{min})$, respectively $(n=280)$. CO varied across a sixfold range (1.9 to $11.7 \mathrm{~L} / \mathrm{min}$ ) during the experiment. The mean percentage bias and precision between paired measures for FP and PAC were $-17.2 \%$ and $47.0 \%$ (Limits of agreement (LOA) -64.2 to 29.9), for FP and USCOM these were $1.0 \%$ and $36.4 \%$ (LOA -35.3 to 37.4 ), and FP and cPAC $-0.2 \%$ and $54.4 \%$ (LOA -53.6 to 53.1 ) (Table 1, Figures 1, 2, 3 , and 4). Calibration of PAC to the FP, cPAC, improved the bias when compared with FP from $-17.2 \%$ to $-0.2 \%$, but the error in precision increased from $47.0 \%$ to $54.4 \%$.

Regression analysis demonstrated a correlation between $\mathrm{FP}$ and PAC of $y=0.780 x+1.679 \mathrm{~L} / \mathrm{min}$, compared with correlations of $y=0.927 x+0.308 \mathrm{~L} / \mathrm{min}$ for FP and USCOM and $y=0.634 x+1.521 \mathrm{~L} / \mathrm{min}$ for FP and cPAC. Pearson correlation across all CO measurements by FP and PAC was

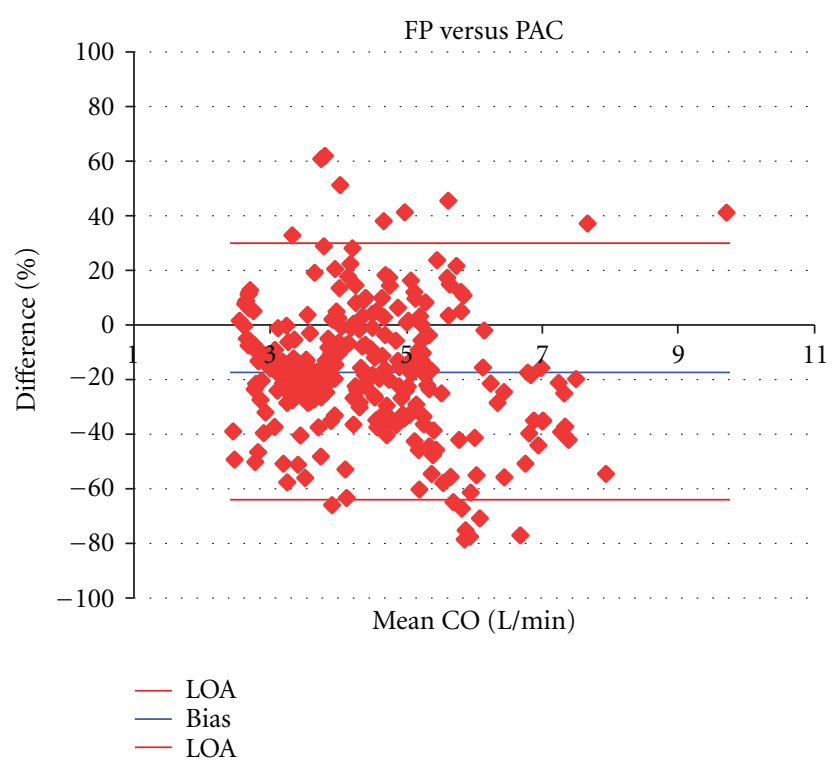

FIgUre 2: Bland Altman plots of FP versus PAC showing bias $(-17.2 \%)$ and LOAs $(-64.2 \%$ and $29.8 \%)$.

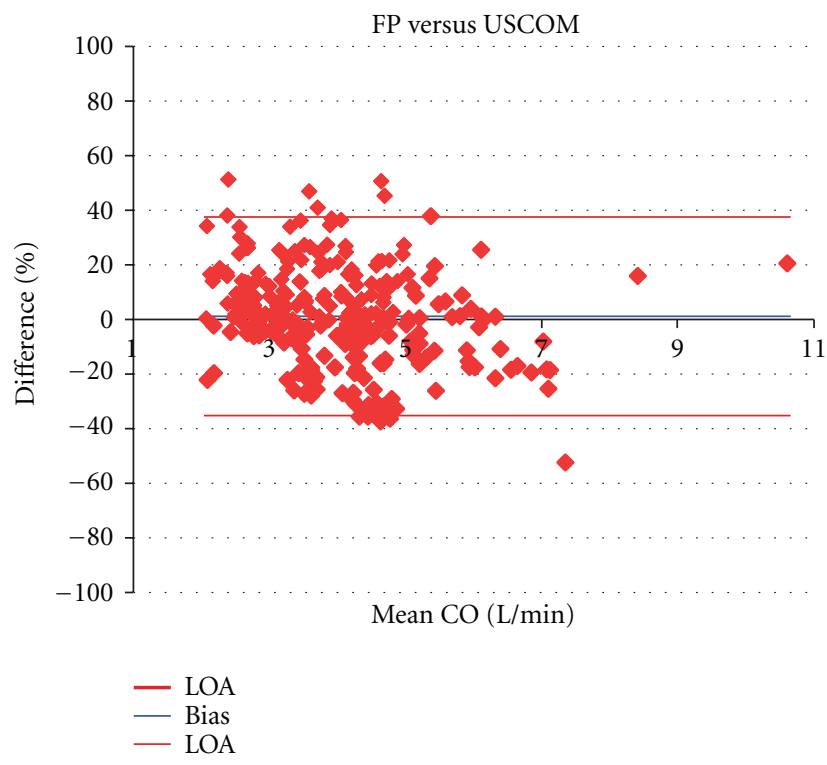

FIGURE 3: Bland Altman plots of FP versus USCOM showing bias $(1 \%)$ and LOAs $(-35.3 \%$ and $37.4 \%)$.

$r=0.604$, while for FP and USCOM it was $r=0.813$, and for FP and cPAC $r=0.588$.

The mean dobutamine induced CO change from baseline measured by FP was $35 \%$ (3.85 \pm 0.93 to $5.13 \pm 1.31 \mathrm{~L} / \mathrm{min})$ while for PAC the measured dobutamine changes were $15 \%$ $(4.70 \pm 1.49$ to $5.31 \pm 1.67 \mathrm{~L} / \mathrm{min})$, an absolute under measurement of $20 \%$ compared to $\mathrm{FP}$, or a relative under measurement of $56 \%$. USCOM measured a $39 \%$ change $(3.67 \pm 0.96$ to $5.04 \pm 1.43 \mathrm{~L} / \mathrm{min}$ ), an absolute difference of $4 \%$, or a relative difference of $10 \%$ from FP. For cPAC the change was $13 \%(3.79 \pm 1.23$ to $4.30 \pm 1.26 \mathrm{~L} / \mathrm{min})$, a $22 \%$ absolute under measurement or a relative under measurement of $63 \%$. 
TABLE 1: Summary of comparison of methods for all paired measures and all sheep as absolute values and $\%$ values $(n=280)$.

\begin{tabular}{|c|c|c|c|c|c|c|}
\hline & Mean $(1 / \min )$ & $\operatorname{Bias}(1 / \mathrm{min})$ & LOAs $(\mathrm{L} / \mathrm{min})$ & Bias \% & Precision $\%$ & LOAs $\%$ \\
\hline FP versus PAC & $4.4 \pm 1.3$ & $-0.8 \pm 1.3$ & -3.3 to 1.7 & -17.2 & 47.0 & -64.2 to 29.9 \\
\hline $\begin{array}{l}\text { FP versus } \\
\text { USCOM }\end{array}$ & $4.0 \pm 1.2$ & $0.0 \pm 0.8$ & -1.6 to 1.6 & 1.0 & 36.4 & -35.3 to 37.4 \\
\hline $\mathrm{FP}$ versus $\mathrm{cPAC}$ & $4.0 \pm 1.1$ & $-0.1 \pm 1.2$ & -3.0 to 1.8 & -0.2 & 54.4 & -54.7 to 54.2 \\
\hline
\end{tabular}

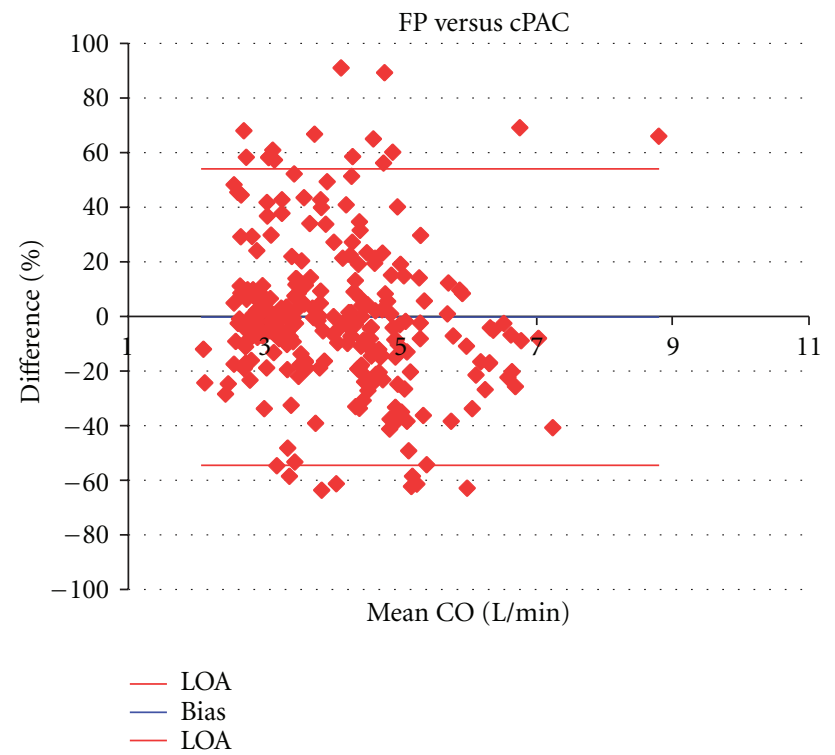

FIgUre 4: Bland Altman plots of FP versus cPAC showing bias $(0.2 \%)$ and LOAs $(-54.7 \%$ and $54.2 \%)$.

The decrease in CO induced by AVP was $13.7 \pm 7.35 \%$ for FP, $9.5 \pm 10.5 \%$ for PAC, $5.3 \pm 17.5 \%$ for USCOM, and $4 \pm 13.5 \%$ for cPAC (Table 2).

Reliable sensitivity to CO change, ROC AUC $>0.70$, was achieved by PAC for changes in excess of $-30 \%$ but not $+40 \%$, with AUC values for $\pm 5 \%$ changes being 0.524 and 0.496 , respectively, indicating random values (Figures 5 and 6). USCOM reliably detected all incremental CO changes down to $\pm 5 \%$, where AUC values were 0.708 and 0.715 . USCOM was more sensitive to CO change than PAC for all values from $-40 \%$ to $+40 \%$ (Table 3 ).

Calibration of the PAC to the FP improved the agreement but not the precision nor sensitivity of the method (Table 1).

The FP calibration of USCOM allowed calculation of sheep PV from a regression equation relating sheep weight $(\mathrm{kg})$, where $\mathrm{PV}=0.0132$ weight $+1.0329 \mathrm{~cm}$.

\section{Discussion}

Despite no history of validation or efficacy, PAC has been a clinical standard for hemodynamic measurement, diagnosis and monitoring, and applied as a research method and reference standard against which new CO measurement methods have been compared. This study found that PAC was an inaccurate measure of $\mathrm{CO}$ and was unreliable for detection of CO changes less than $30-40 \%$. These findings may

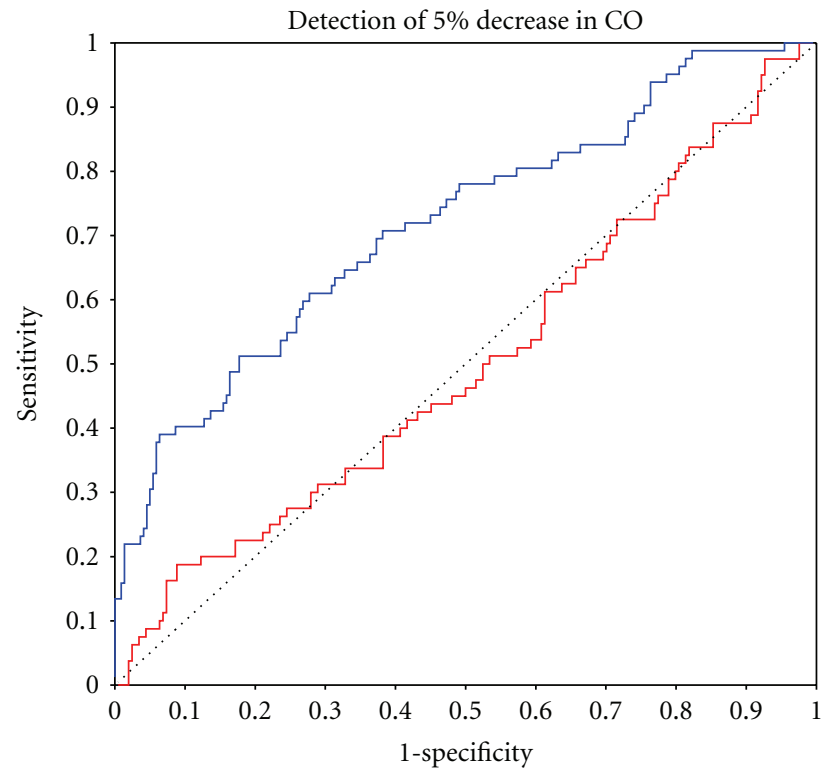

Figure 5: ROC curve for 70\% certainty of detection of 5\% decrease in CO from baseline with PAC in red (AUC $=0.496)$, USCOM in blue (AUC $=0.715)$. Random values are represented by the dotted line $(\mathrm{AUC}=0.50)$ and clinical effectiveness $\mathrm{AUC} \geq 0.70$.

explain the absence of reported outcomes benefit associated with PAC use and raises questions as to its continued use as a gold standard hemodynamic monitor. USCOM demonstrated equivalence to FP measures across COs from 1.9 to $11.7 \mathrm{~L} / \mathrm{min}$, and reliably detected $\pm 5 \%$ changes in $\mathrm{CO}$.

Prior comparison studies generally demonstrate USCOM to have acceptable agreement with PAC but good agreement with proven $\mathrm{CO}$ measures such as FPs and external cardiac pumps. Prior comparisons of USCOM with PAC in postcardiac surgical critical care patients have reported bias's of $12 \%, 18 \%$, and $19 \%$ [43-45], similar to the $18 \%$ found in this study. While mean errors in precision reported for USCOM PAC comparisons in a variety of clinical groups averaged $30 \%$ [28-33, 37, 43-46], the recommended acceptable cutoff value [47]. However, comparisons between USCOM and non-PAC methods have demonstrated superior agreement. Critchley et al. compared USCOM with FPs in dogs and found a bias of less than $1 \%$ and an error in precision of $13 \%$ across 319 paired measures [25]. In heart failure patients USCOM CO measures demonstrated a bias of less than $1 \%$ and an error in precision of less than $10 \%$ when compared with values from external circulatory pumps driving transplanted artificial hearts [27]. The results from the current side-by-side study demonstrate that PAC compares poorly 
TABLE 2: Mean percentage change of CO from baseline (0\%) at each intervention and recovery time-point in all sheep by each method.

\begin{tabular}{lccccc}
\hline \% Difference & Baseline & Dobutamine & Post Dob & Vasopressor & Post Vaso \\
\hline FP & 0 & 35.4 & 1.2 & -13.7 & -13.2 \\
PAC & 0 & 15.7 & 32.5 & -9.5 & -16.3 \\
USCOM & 0 & 39.1 & 5.7 & -5.3 & -4.1 \\
cPAC & 0 & 13.2 & 30.0 & -4.0 & -13.1 \\
\hline
\end{tabular}

TABLE 3: ROC area under the curve (AUC) values for detection of increased and decreased percentage changes of CO relative to FP where $P$ is significance of difference between the two measures. An AUC of 1 represents perfect sensitivity, 0.7 represents clinically acceptable sensitivity to change, while 0.5 is a random relationship.

\begin{tabular}{lccccccccccccc}
\hline & $-40 \%$ & $-30 \%$ & $-20 \%$ & $-15 \%$ & $-10 \%$ & $-5 \%$ & $+5 \%$ & $+10 \%$ & $+15 \%$ & $+20 \%$ & $+30 \%$ & $+40 \%$ \\
\hline PAC & 0.855 & 0.811 & $\mathbf{0 . 6 3 5}$ & $\mathbf{0 . 5 4 9}$ & $\mathbf{0 . 5 3 4}$ & $\mathbf{0 . 4 9 6}$ & $\mathbf{0 . 5 2 4}$ & $\mathbf{0 . 5 8 5}$ & $\mathbf{0 . 6 3 1}$ & $\mathbf{0 . 6 5 9}$ & $\mathbf{0 . 6 3 1}$ & $\mathbf{0 . 6 2 1}$ \\
USCOM & 0.897 & 0.881 & 0.885 & 0.857 & 0.842 & 0.714 & 0.708 & 0.754 & 0.812 & 0.814 & 0.790 & 0.897 \\
$P$ & 0.45 & 0.3 & 0.004 & 0.000 & 0.000 & 0.000 & 0.000 & 0.005 & 0.01 & 0.04 & 0.094 & 0.06 \\
\hline
\end{tabular}

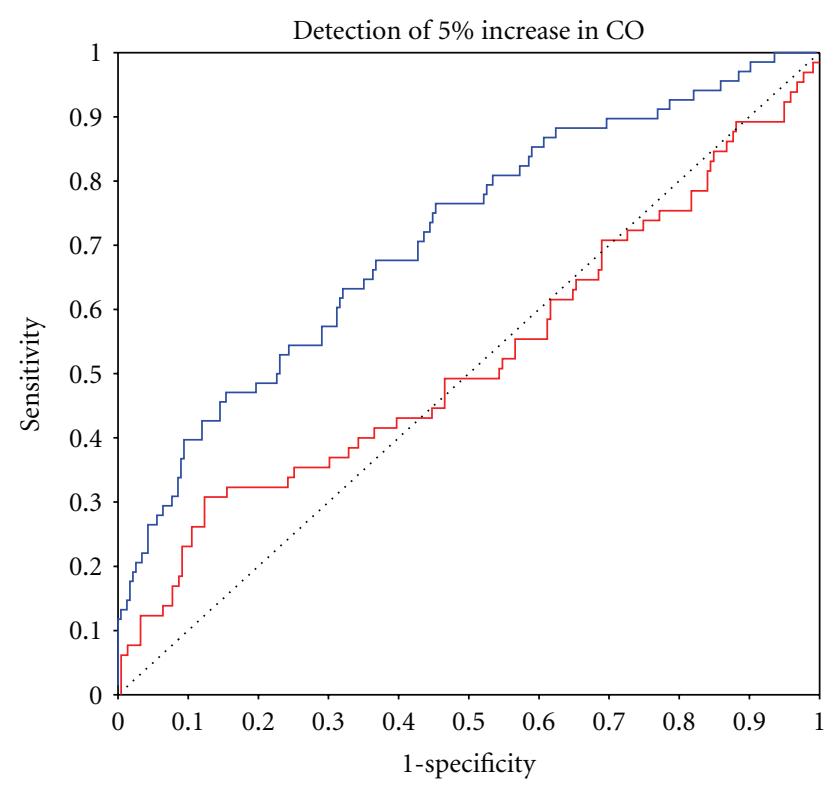

FIGURE 6: ROC curve for 70\% certainty of detection of 5\% increase in CO from baseline with PAC in red (AUC $=0.524)$, USCOM in blue (AUC $=0.708)$. Random values are represented by the dotted line $(\mathrm{AUC}=0.50)$ and clinical effectiveness $\mathrm{AUC} \geq 0.70$.

with both FP and USCOM as a measure and monitor of CO, findings consistent with the prior studies.

The Bland Altman method is the standard statistical method for comparison of two clinical methods [39], and PAC has been the preferred reference method for validation studies. However, PAC coefficient of variation (COV), an index of repeatability, is high, being on average $28 \%$ in 8 human comparison studies with USCOM $[28,30,32,33,37$, $43,44,46]$. Therefore it is almost mathematically impossible for even a perfect reference method to achieve less than a $30 \%$ error of precision compared with PAC [47]. This limitation of bias and precision analysis was noted by Bland and Altman [48] and confirms that the poor reproducibility of PAC limits its performance as a reference standard for
CO method comparisons. In this study FP versus USCOM errors in precision were smaller than those of FP versus PAC, $36 \%$ versus $47 \%$, suggesting that, as the variability of FP is a constant, the increased error in precision reflects the increased variability of PAC alone. In clinical practice this poor intrinsic repeatability of PAC is acknowledged by the averaging of 3 measurements that fall within $10 \%$ of each other to achieve a clinically acceptable measure [46]. This methodological bias may reject 3 or more PAC measures which would otherwise contribute to true PAC variability and increase the underlying COV.

Measurement of circulatory change is central to the function of hemodynamic monitoring, with detection of $15 \%$ changes in CO considered to be clinically desirable $[46,49]$. However, $15 \%$ sensitivity is rarely achieved by current monitoring methods, with PAC sensitivity reported to be in the order of $30 \%$ [47], similar to the $30-40 \%$ found in this study. Walker et al. found CW Doppler sensitivity in hemodynamics models to be $2.3 \%$ [24], while trans-aortic CW Doppler measured minute distance (MD), a cross-sectional area independent measure of output, has a reported sensitivity of $11 \%$ and $20 \%[50,51]$. In this study USCOM was found to reliably detect $\pm 5 \%$ changes in CO $70 \%$ of the time while $15 \%$ changes were detected with 80 to $85 \%$ certainty (Table 3 ). This high sensitivity is predicted by Moulinier et al. [50] who identified an $11 \%$ sensitivity of a single repeated Doppler CO/SV measure. Further Moulinier demonstrated that with repeated observations this sensitivity was increased by a function of $1 / \sqrt{n}$, where $n$ is the number of repeated observations averaged to constitute the reference measure. The mean number of repeated observations in this study was 9 (range 6-12), meaning the predicted sensitivity of USCOM, using generalizability theory and 9 repeated measures, is $11 \% \times 1 / \sqrt{9}$ or $4 \%$, a value similar to the sensitivity determined by the ROC AUC statistic of $5 \%$ found in this study. PAC, using the same AUC $>0.70$ to define acceptable sensitivity, detected a $-30 \%$ change in CO but not a $+40 \%$ change relative to the FP (Table 3 ), a value broadly in line with prior studies. Boyle et al, in a PAC USCOM comparison in ICU patients, found an AUC of $67 \%$ for detection 
of $15 \%$ changes [43], while in a similar comparison Thom et al. found a 50\% sensitivity for detecting $15 \%$ changes [44]. However, these comparisons with PAC as the reference standard prove only that one of the methods, PAC or USCOM, is insensitive to change and not which method is inaccurate. The current study suggests that the insensitivity of PAC is the source of this disagreement and not, as Boyle and Thom hypothesised, the unreliability of USCOM.

The current data also demonstrate that PAC under measured the $\mathrm{CO}$ change associated with inotropic intervention, a critical and common intervention in the deranged circulation, by $20 \%$ (relative $66 \%$ ) compared with the FP, while USCOM differed by $4 \%$ (relative 10\%). The differences between measured $\mathrm{CO}$ changes associated with vasopressors, where the hemodynamic changes were smaller, were less marked (Table 2). This study of normal sheep determined that the mean inotropic reserve associated with a standard weight indexed dobutamine dose was approximately $35 \%$, and that a normal vasopressor dose reduced $\mathrm{CO}$ by approximately $14 \%$.

While experimental measures of accuracy provide insight into the theoretical capability of a modality, clinical utility remains the test of effectiveness of a method, and a number of studies have been conducted to establish the clinical utility of PAC.

Connors et al. in a multicentre RCT demonstrated a relative increase in mortality of $26 \%$ and an increase in hospital costs by $38 \%$ associated with PAC use in 5,735 critically ill patients [19]. Shah et al. in a meta-analysis of 13 randomised controlled trials (RCT) between 1985 and 2005 studying PAC use in 5,051 critically ill patients found no mortality benefit or reduced in hospital stay despite an increased use of inotropes and vasodilators [2] in PAC patients. The ESCAPE trial, a 26 centre prospective RCT of PAC use in 433 acute heart failure patients was prematurely halted when the National Heart, Lung, and Blood Institute Data Safety Monitoring Board cited concerns about excess adverse events and little likelihood of a positive outcome [4]. The American Society of Anesthesiology in a literature review identified an associated mortality of 0.2 to $1.5 \%$ with PAC use, and an incidence of catheter tip infection in excess of $19 \%$ and an attributable sepsis rate of 0.7 to $3 \%$ [18].

A commonly cited benefit of PAC is that it provides filling pressures which can be used to identify fluid responsiveness and guide fluid administration. However, these filing pressures have been found to be neither uniformly accurate [52], nor effective [2, 42, 52] for fluid guidance with Marick et al. demonstrating an AUC of 0.56 [42]. USCOMmeasured SV changes with autologous physiologic challenges have been shown to detect fluid responsiveness with a positive predictive value of $91 \%$ in a patient group that included subjects in atrial fibrillation, on and off mechanical ventilation, and on vasopressors [53]. In the same study the invasively measured central venous pressure (CVP) and mean arterial pressure (MAP) were not significantly predictive of fluid responsiveness with ROC AUC values of 0.52 and 0.62 , respectively. Further Sturgess et al. [49] in a study of septic subjects identified a correlation of 0.81 between USCOM measured corrected flow time (FTc) with fluid responsiveness, while CVP and brain natriuretic peptide (BNP) showed no significant correlation with fluid responsiveness, $r=0.4$ and 0.3 , respectively. Both of these studies relied on the sensitive detection of small incremental changes in flow volume (CO/SV) using USCOM to describe an individual patient's Frank Starling curve and identify fluid responsiveness, a utility which remains unproven in PAC.

The accuracy of CO/SV measures determined by USCOM is dependent on the accuracy of the prediction of the valve area and any error in this calculation will convert directly to an error in CO/SV. Two studies have reported poor agreement of transthoracic and transesophageal echocardiographic measurement of the aortic valve (AV) and pulmonary valve (PV) diameter compared with the morphometrically determined USCOM values. These studies consequently reported poor agreement of echocardiographic, and PAC determined CO values $[54,55]$. USCOM's morphometrically calibrated Doppler method is based on height and weight determined $\mathrm{AV}$ and PV annular diameters to calculate flow volumes, with the algorithm derived from normal 2D echocardiographic data [56]. While the 2D echocardiographic measurement of valve diameters requires meticulous methodology for accurate results [57] and has significant associated errors, Capps et al. made direct measurement of the AV and PV diameters of 6801 cardiac donors using Hegar dilators and derived morphometric regression equations with values which approximate those of the USCOM algorithms [58]. Alternatively, the AV or PV diameter, measured by another method such as echocardiography or MRI, can be manually input to over ride the USCOM algorithm and preserve reliability, or a CSA-independent method such as MD, can be used to track changes and monitor central circulation changes.

The outcomes benefits of hemodynamic optimization seem intuitive and are the rationale for circulatory interventions with fluid, inotropes, and vaso-active therapies. In presurgical patients hemodynamic optimization has been demonstrated in a 29 study meta-analysis to produce a decrease in overall mortality (7.6\%) and morbidity [59]. While the impact of circulatory optimization in septic shock has an even greater impact with a reported reduction in mortality of $16 \%$ (relative $34 \%$ ) in adults, and $27.4 \%$ (relative $70 \%$ ) in children $[60,61]$. A noninvasive device which can rapidly and accurately provide physiologically rational goals such as SV and SVR for guidance of fluid, inotropes and vasoactive therapies may increase the adoption of effective hemodynamic strategies across a variety of clinical applications and take advanced hemodynamics beyond the critical care.

4.1. Limitations. The PAC is used for $\mathrm{CO}$ measurement in sheep and as a cardiovascular research tool, while the USCOM algorithms were developed in human subjects. To compensate the USCOM device was calibrated to baseline FP measures, and this may have conferred some benefit to the FP/USCOM bias comparison. However, calibration data were excluded from analysis and $76 \%$ of all measurements were made after interventions which altered $\mathrm{CO}$ across a sixfold range ( 1.9 to $11.7 \mathrm{~L} / \mathrm{min}$ ), thus mitigating any conferred benefits from calibration. Additionally the interventional component of the study, designed to assess sensitivity to $\mathrm{CO}$ 
change, involved calibrating all methods to a nominal zero baseline, thus removing any advantage for any method. As a further precaution a calibrated PAC series, cPAC, was generated post hoc to address any methodological bias in the study.

We found a $20 \%$ failure rate of PAC during the monitoring of normal sheep. We hypothesised that as CCO PAC has a thermometrically triggered safety cutoff, and that the normal body temperature of sheep is $39^{\circ}$ to $39.9^{\circ} \mathrm{C}$ [62], higher than that of humans, $37^{\circ} \mathrm{C}[63]$, this may have triggered the cutoff. However, we have no explanation for this high PAC failure rate which may be a limitation of this study.

This study was of a continuous $\mathrm{CO}$ iteration of PAC, $\mathrm{CCO}$, and so some of the observations may not be interchangeable with bolus thermodilution. However, CCO is a thermodilution method and has been adopted on the basis of very good to excellent agreement with iced bolus thermodilution [64].

The FP was implanted around the ascending aorta measuring left heart CO while both PAC and USCOM measured right $\mathrm{CO}$; however, in the absence of a shunt and disregarding coronary flow, the values should equate and the comparison remain valid.

The PAC was sited in the pulmonary artery throughout the studies, and would have caused some disturbance to the flow characteristics measured by USCOM. This limitation of the catheter measurements cannot be overcome in the current preparation, and would also be a confounding factor in clinical practice.

4.2. Conclusion. This study found that PAC was neither accurate nor sensitive when compared with the FP, findings which may explain the apparent ineffectiveness of PAC in clinical practice. This study also found that USCOM provided equivalent $\mathrm{CO}$ measurements to $\mathrm{FP}$ and is a noninvasive and accurate alternative to PAC reliably detecting $\pm 5 \%$ changes in CO.

\section{Conflict of Interests}

An USCOM 1A device was lent to the Howard Florey Institute for the purposes of this study. R. A. Phillips and B. M. Jacobson are shareholders and employees of Uscom Ltd.

\section{Acknowledgments}

Thanks are due to Simon Parker for statistical support, and Brendan Smith, Joe Brierley, David Bennett, Darryl Burstow, and John Fraser.

\section{References}

[1] H. J. Swan, W. Ganz, J. Forrester, H. Marcus, G. Diamond, and D. Chonette, "Catheterization of the heart in man with use of a flow-directed balloon-tipped catheter," New England Journal of Medicine, vol. 283, no. 9, pp. 447-451, 1970.

[2] M. R. Shah, V. Hasselblad, L. W. Stevenson et al., "Impact of the pulmonary artery catheter in critically ill patients: metaanalysis of randomized clinical trials," Journal of the American Medical Association, vol. 294, no. 13, pp. 1664-1670, 2005.
[3] National Heart, Lung, and Blood Institute Acute Respiratory Distress Syndrome (ARDS) Clinical Trials Network, "Pulmonary-artery versus central venous catheter to guide treatment of acute lung injury," The New England Journal of Medicine, vol. 354, no. 21, pp. 2213-2224, 2006.

[4] L. W. Stevenson and The ESCAPE investigators and ESCAPE coordinators, "Evaluation study of congestive heart failure and pulmonary artery catheterization effectiveness," Journal of the American Medical Association, vol. 294, no. 13, pp. 1625-1633, 2005.

[5] N. M. Schwann, Z. Hillel, A. Hoeft et al., "Lack of effectiveness of the pulmonary artery catheter in cardiac surgery," Anesthesia \& Analgesia, vol. 113, no. 5, pp. 994-1002, 2011.

[6] R. G. Cigarroa, R. A. Lange, R. H. Williams, J. B. Bedotto, and L. D. Hillis, "Underestimation of cardiac output by thermodilution in patients with tricuspid regurgitation," American Journal of Medicine, vol. 86, no. 4, pp. 417-420, 1989.

[7] G. F. Maruschak, A. M. Potter, J. F. Schauble, and M. C. Rogers, "Overestimation of pediatric cardiac output by thermal indicator loss," Circulation, vol. 65, no. 2, pp. 380-383, 1982.

[8] M. G. Bazaral, J. Petre, and R. Novoa, "Errors in thermodilution cardiac output measurements caused by rapid pulmonary artery temperature decreases after cardiopulmonary bypass," Anesthesiology, vol. 77, no. 1, pp. 31-37, 1992.

[9] T. W. Latson, C. W. Whitten, and D. O'Flaherty, "Ventilation, thermal noise, and errors in cardiac output measurements after cardiopulmonary bypass," Anesthesiology, vol. 79, no. 6, pp. 1233-1243, 1993.

[10] T. Nishikawa and S. Dohi, "Errors in the measurement of cardiac output by thermodilution," Canadian Journal of Anaesthesia, vol. 40, no. 2, pp. 142-153, 1993.

[11] V. K. Dhingra, J. C. Fenwick, K. R. Walley, D. R. Chittock, and J. J. Ronco, "Lack of agreement between thermodilution and Fick cardiac output in critically ill patients," Chest, vol. 122, no. 3, pp. 990-997, 2002.

[12] J. D. Mackenzie, N. E. Haites, and J. M. Rawles, "Method of assessing the reproducibility of blood flow measurement: factors influencing the performance of thermodilution cardiac output computers," British Heart Journal, vol. 55, no. 1, pp. 14-24, 1986.

[13] M. Yelderman, M. D. Quinn, R. C. McKown, R. C. Eberhart, and M. L. Dollar, "Continuous thermodilution cardiac output measurement in sheep," Journal of Thoracic and Cardiovascular Surgery, vol. 104, no. 2, pp. 315-320, 1992.

[14] M. L. Yelderman, M. A. Ramsay, M. D. Quinn, A. W. Paulsen, R. C. McKown, and P. H. Gillman, "Continuous thermodilution cardiac output measurement in intensive care unit patients," Journal of Cardiothoracic and Vascular Anesthesia, vol. 6, no. 3, pp. 270-274, 1992.

[15] C. Patel, V. Laboy, and B. Venus, "Acute complications of pulmonary artery catheter insertion in critically ill patients," Critical Care Medicine, vol. 14, no. 3, pp. 195-197, 1986.

[16] T. Bossert, J. F. Gummert, H. B. Bittner et al., "Swan-Ganz catheter-induced severe complications in cardiac surgery: right ventricular perforation, knotting, and rupture of a pulmonary artery," Journal of Cardiac Surgery, vol. 21, no. 3, pp. 292-295, 2006.

[17] D. R. Chittock, V. K. Dhingra, J. J. Ronco et al., "Severity of illness and risk of death associated with pulmonary artery catheter use," Critical Care Medicine, vol. 32, no. 4, pp. 911$915,2004$.

[18] American Society of Anesthesiologists Task Force on Pulmonary Artery Catheterization, "Practice guidelines for pulmonary artery catheterization: an updated report by the 
American Society of Anesthesiologists Task Force on Pulmonary Artery Catheterization," Anesthesiology, vol. 99, no. 4, pp. 988-1014, 2003.

[19] A. F. Connors, T. Speroff, N. V. Dawson et al., "The effectiveness of right heart catheterization in the initial care of critically ill patients," Journal of the American Medical Association, vol. 276, no. 11, pp. 889-897, 1996.

[20] M. B. Jaffe, "Partial $\mathrm{CO}_{2}$ rebreathing cardiac output-operating principles of the NICO system," Journal of Clinical Monitoring and Computing, vol. 15, no. 6, pp. 387-401, 1999.

[21] P. J. Peyton, Y. Wenkatesan, S. G. Hood, P. Junor, and C. N. May, "Noninvasive, automated and continous cardiac output monitoring by pulmonary capnodynamics: breath-by-breath comparison with ultrasonic flow probe," Anesthiology, vol. 105 , no. 1 , pp. $72-80,2006$.

[22] F. Michard, D. Chemla, C. Richard et al., "Clinical use of respiratory changes in arterial pulse pressure to monitor the hemodynamic effects of PEEP," American Journal of Respiratory and Critical Care Medicine, vol. 159, no. 3, pp. 935939, 1999.

[23] P. M. Dark and M. Singer, "The validity of trans-esophageal Doppler ultrasonography as a measure of cardiac output in critically ill adults," Intensive Care Medicine, vol. 30, no. 11, pp. 2060-2066, 2004.

[24] A. Walker, E. Olsson, B. Wranne, I. Ringqvist, and P. Ask, "Accuracy of spectral Doppler flow and tissue velocity measurements in ultrasound systems," Ultrasound in Medicine and Biology, vol. 30, no. 1, pp. 127-132, 2004.

[25] L. A. Critchley, Z. Y. Peng, B. S. Fok, A. Lee, and R. A. Phillips, "Testing the reliability of a new ultrasonic cardiac output monitor, the USCOM, by using aortic flowprobes in anesthetized dogs," Anesthesia and Analgesia, vol. 100, no. 3, pp. 748-753, 2005.

[26] R. A. Phillips, M. Paradisis, N. J. Evans, D. L. Southwell, M. J. West, and D. J. Burstow, "Validation of USCOM $\mathrm{CO}$ measurements in preterm neonates by comparison with echocardiography," Critical Care Medicine, vol. 10, supplement 1, pp. 144-343, 2006.

[27] R. A. Phillips, P. R. Lichtenthal, J. A. Sloniger, D. J. Burstow, M. J. West, and J. G. Copleand, "Noninvasive cardiac output measurement in heart failure subjects on circulatory support," Anesthesia \& Analgesia, vol. 108, no. 3, pp. 881-886, 2009.

[28] K. Knobloch, A. Lichtenberg, M. Winterhalter, D. Rossner, M. Pichlmaier, and R. Phillips, "Non-invasive cardiac output determination by two-dimensional independent Doppler during and after cardiac surgery," Annals of Thoracic Surgery, vol. 80, no. 4, pp. 1479-1483, 2005.

[29] H. L. Tan, M. Pinder, R. Parsons, B. Roberts, and P. V. van Heerden, "Clinical evaluation of USCOM ultrasonic cardiac output monitor in cardiac surgical patients in intensive care unit," British Journal of Anaesthesia, vol. 94, no. 3, pp. 287-291, 2005.

[30] R. Chand, Y. Mehta, and N. Trehan, "Cardiac output estimation with a new Doppler device after off-pump coronary artery bypass surgery," Journal of Cardiothoracic and Vascular Anesthesia, vol. 20, no. 3, pp. 315-319, 2006.

[31] D. Arora, R. Chand, Y. Mehta, and N. Trehan, "Cardiac output estimation after off-pump coronary artery bypass: a comparison of two different techniques," Annals of Cardiac Anaesthesia, vol. 10, no. 2, pp. 132-136, 2007.

[32] B. C. Su, H. P. Yu, M. W. Yang et al., "Reliability of a new ultrasonic cardiac output monitor in recipients of living donor liver transplantation," Liver Transplantation, vol. 14, no. 7, pp. 1029-1037, 2008.
[33] L. S. G. Wong, B. H. Yong, K. K. Young et al., "Comparison of the USCOM ultrasound cardiac output monitor with pulmonary artery catheter thermodilution in patients undergoing liver transplantation," Liver Transplantation, vol. 14, no. 7, pp. 1038-1043, 2008.

[34] H. B. Nguyen, T. Losey, J. Rasmussen et al., "Interrater reliability of cardiac output measurements by transcutaneous Doppler ultrasound: implications for noninvasive hemodynamic monitoring in the ED," American Journal of Emergency Medicine, vol. 24, no. 7, pp. 828-835, 2006.

[35] G. M. Stewart, H. B. Nguyen, T. Y. Kim, J. Jauregui, S. R. Hayes, and S. Corbett, "Inter-rater reliability for noninvasive measurement of cardiac function in children," Pediatric Emergency Care, vol. 24, no. 7, pp. 433-437, 2008.

[36] G. N. Cattermole, P. Y. M. Leung, P. S. K. Mak, S. S. W. Chan, C. A. Graham, and T. H. Rainer, "The normal ranges of cardiovascular parameters in children measured using the Ultrasonic Cardiac Output Monitor," Critical Care Medicine, vol. 38, no. 9, pp. 1875-1881, 2010.

[37] S. Jain, A. Allins, A. Salim, A. Vafa, M. T. Wilson, and D. R. Margulies, "Noninvasive Doppler ultrasonography for assessing cardiac function: can it replace the Swan-Ganz catheter?" American Journal of Surgery, vol. 196, no. 6, pp. 961968, 2008.

[38] D. A. Dean, C. X. Jia, S. E. Cabreriza et al., "Validation study of a new transit time ultrasonic flow probe for continuous great vessel measurements," ASAIO Journal, vol. 42, no. 5, pp. M671-M676, 1996.

[39] D. G. Altman and J. M. Bland, "Measurement in medicine: the analysis of method comparison studies," The Statistician, vol. 32, no. 3, pp. 307-317, 1983.

[40] J. A. Hanley and B. J. McNeil, "A method of comparing the areas under receiver operating characteristic curves derived from the same cases," Radiology, vol. 148, no. 3, pp. 839-843, 1983.

[41] M. H. Zweig and G. Campbell, "Receiver-operating characteristic (ROC) plots: a fundamental evaluation tool in clinical medicine," Clinical Chemistry, vol. 39, no. 4, pp. 561-577, 1993.

[42] P. E. Marik, M. Baram, and B. Vahid, "Does central venous pressure predict fluid responsiveness?" Chest, vol. 134, no. 1, pp. 172-178, 2008.

[43] M. Boyle, L. Steel, G. M. Flynn et al., "Assessment of the clinical utility of an ultrasonic monitor of cardiac output (the USCOM) and agreement with thermodilution measurement," Critical Care and Resuscitation, vol. 11, no. 3, pp. 198-203, 2009.

[44] O. Thom, D. M. Taylor, R. E. Wolfe et al., "Comparison of a supra-sternal cardiac output monitor (USCOM) with the pulmonary artery catheter," British Journal of Anaesthesia, vol. 103, no. 6, pp. 800-804, 2009.

[45] L. E. M. van Lelyveld-Haas, A. R. H. van Zanten, G. F. Borm, and D. H. T. Tjan, "Clinical validation of the non-invasive cardiac output monitor USCOM-1A in critically ill patients," European Journal of Anaesthesiology, vol. 25, no. 11, pp. 917924, 2008.

[46] A. Corley, A. G. Barnett, D. Mullany, and J. F. Fraser, "Nursedetermined assessment of cardiac output. Comparing a noninvasive cardiac output device and pulmonary artery catheter: a prospective observational study," International Journal of Nursing Studies, vol. 46, no. 10, pp. 1291-1297, 2009.

[47] L. A. H. Critchley and J. A. J. H. Critchley, "A meta-analysis of studies using bias and precision statistics to compare cardiac output measurement techniques," Journal of Clinical Monitoring and Computing, vol. 15, no. 2, pp. 85-91, 1999. 
[48] J. M. Bland and D. G. Altman, "Statistical methods for assessing agreement between two methods of clinical measurement," The Lancet, vol. 1, no. 8476, pp. 307-310, 1986.

[49] D. J. Sturgess, R. L. S. Pascoe, B. Venkatesh, and G. Scalia, "A comparison of transcutaneous Doppler corrected flow time, b-type natriuretic peptide and central venous pressure as predictors of fluid responsiveness in septic shock: a preliminary study," Anaesthesia and Intensive Care Journal, vol. 38, no. 2, pp. 336-341, 2009.

[50] L. Moulinier, T. Venet, N. B. Schiller, T. W. Kurtz, R. C. Morris, and A. Sebastian, "Measurement of aortic blood flow by Doppler echocardiography: day to day variability in normal subjects and applicability in clinical research," Journal of the American College of Cardiology, vol. 17, no. 6, pp. 1326-1333, 1991.

[51] H. Ihlen, K. Endresen, Y. Myreng, and E. Myhre, "Reproducibility of cardiac stroke volume estimated by Doppler echocardiography," American Journal of Cardiology, vol. 59, no. 9, pp. 975-978, 1987.

[52] T. J. Iberti, E. P. Fischer, A. B. Leibowitz, E. A. Panacek, J. H. Silverstein, and T. E. Albertson, "A multicenter study of physicians' knowledge of the pulmonary artery catheter," Journal of the American Medical Association, vol. 264, no. 22, pp. 29282932, 1990.

[53] S. W. Thiel, M. H. Kollef, and W. Isakow, "Non-invasive stroke volume measurement and passive leg raising predict volume responsiveness in medical ICU patients: an observational cohort study," Critical Care, vol. 13, no. 4, Article ID R111, 2009.

[54] H. B. Nguyen, D. P. Banta, G. Stewart et al., "Cardiac index measurements by transcutaneous doppler ultrasound and transthoracic echocardiography in adult and pediatric emergency patients," Journal of Clinical Monitoring and Computing, vol. 24, no. 3, pp. 237-247, 2010.

[55] H. L. A. van den Oever, E. J. Murphy, and G. A. ChristieTaylor, "USCOM (Ultrasonic Cardiac Output Monitors) lacks agreement with thermodilution cardiac output and transoesophageal echocardiography valve measurements," Anaesthesia and Intensive Care, vol. 35, no. 6, pp. 903-910, 2007.

[56] S. M. Nidorf, M. H. Picard, M. O. Triulzi et al., "New perspectives in the assessment of cardiac chamber dimensions during development and adulthood," Journal of the American College of Cardiology, vol. 19, no. 5, pp. 983-988, 1992.

[57] M. A. Quiñones, C. M. Otto, M. Stoddard, A. Waggoner, and W. A. Zoghbi, "Recommendations for quantification of Doppler echocardiography: a report from the Doppler quantification task force of the nomenclature and standards committee of the American society of echocardiography," Journal of the American Society of Echocardiography, vol. 15, no. 2, pp. 167-184, 2002.

[58] S. B. Capps, R. C. Elkins, and D. M. Fronk, "Body surface area as a predictor of aortic and pulmonary valve diameter," Journal of Thoracic and Cardiovascular Surgery, vol. 119, no. 5, pp. 975-982, 2000.

[59] M. A. Hamilton, M. Cecconi, and A. Rhodes, "A systematic review and meta-analysis on the use of preemptive hemodynamic intervention to improve postoperative outcomes in moderate and high-risk surgical patients," Anesthesia and Analgesia, vol. 112, no. 6, pp. 1392-1402, 2011.

[60] E. Rivers, B. Nguyen, S. Havstad et al., "Early goal-directed therapy in the treatment of severe sepsis and septic shock," New England Journal of Medicine, vol. 345, no. 19, pp. 1368 1377, 2001.
[61] C. F. de Oliveira, D. S. F. de Oliveira, A. F. C. Gottschald et al., "ACCM/PALS haemodynamic support guidelines for paediatric septic shock: an outcomes comparison with and without monitoring central venous oxygen saturation," Intensive Care Medicine, vol. 34, no. 6, pp. 1065-1075, 2008.

[62] K. E. Cooper, N. W. Kasting, K. Lederis, and W. L. Veale, "Evidence supporting a role for endogenous vasopressin in natural suppression of fever in the sheep," Journal of Physiology, vol. 295, pp. 33-45, 1979.

[63] D. I. Sessler, "Mild perioperative hypothermia," New England Journal of Medicine, vol. 336, no. 24, pp. 1730-1736, 1997.

[64] E. R. Schmid, D. Schmidlin, M. Tornic, and B. Seifert, "Continuous thermodilution cardiac output: clinical validation against a reference technique of known accuracy," Intensive Care Medicine, vol. 25, no. 2, pp. 166-172, 1999. 


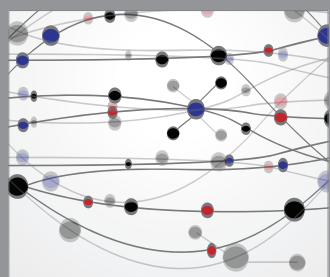

The Scientific World Journal
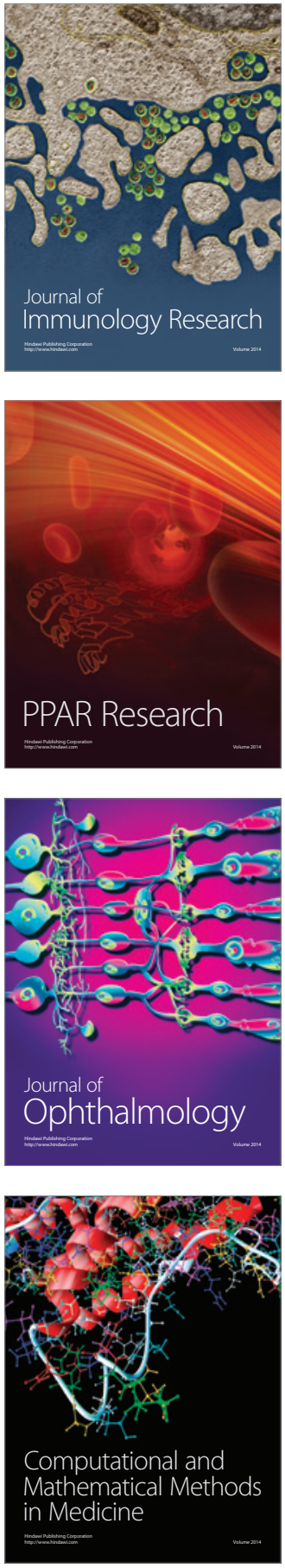

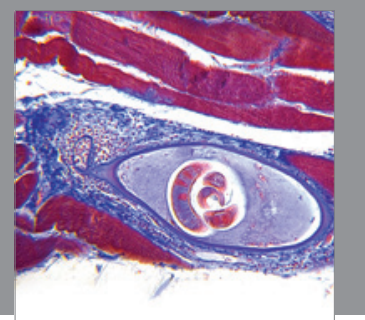

Gastroenterology

Research and Practice
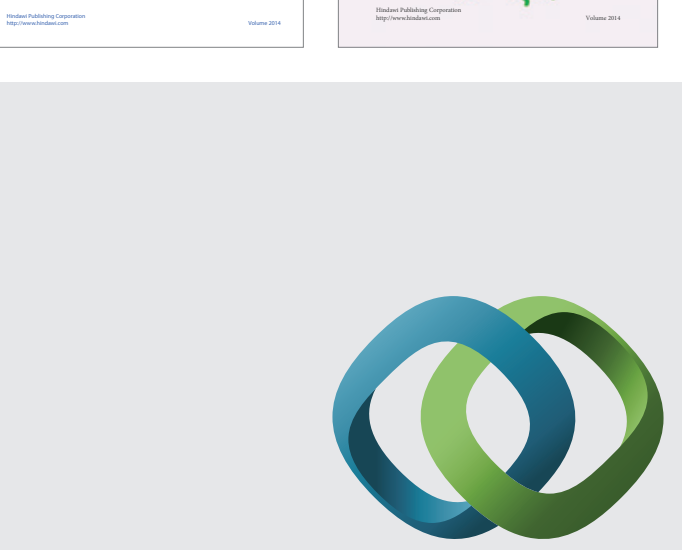

\section{Hindawi}

Submit your manuscripts at

http://www.hindawi.com
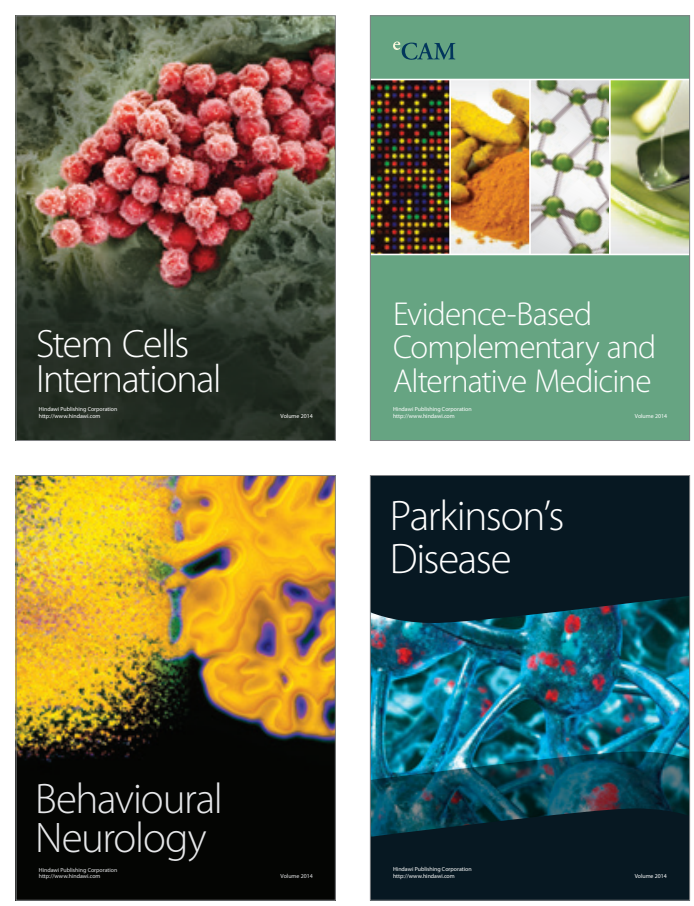

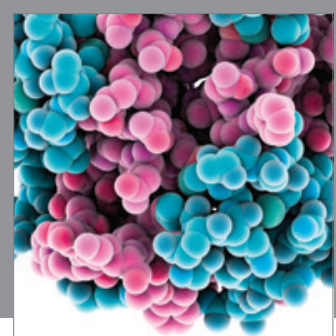

Journal of
Diabetes Research

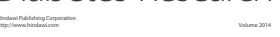

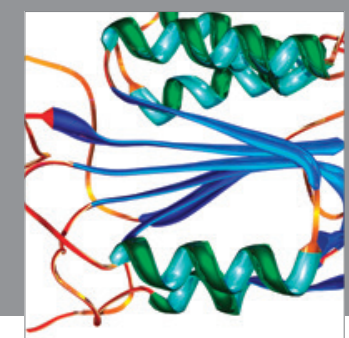

Disease Markers
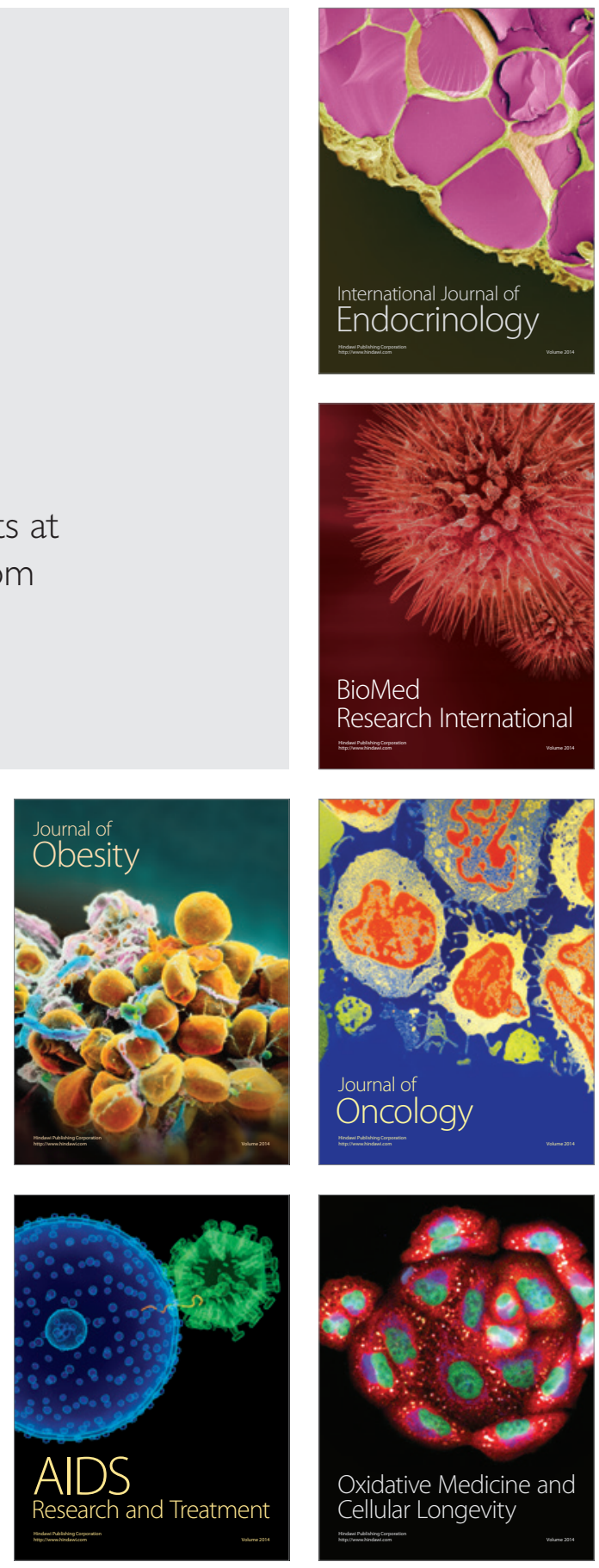